\title{
Working and short-term memory defects in Egyptian dyslexic children
}

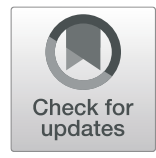

\author{
N. H. Hamouda and R. A. El-Shafaei
}

\begin{abstract}
Background: Memory is the process of encoding, storing, consolidating, and retrieving information. Short-term memory (STM) describes the process of passively holding small amounts of material to be later produced in an untransformed fashion. Tasks that measure STM typically involve situations that do not vary their initial encoding (recall a sequence of items in the order in which they were presented). In children with dyslexia, deficits in working memory have not been well specified.

Results: There is statistically significant between group I and group II regarding all items of the TOMAL-2.

Conclusions: Dyslexic children are distinctively disadvantaged compared with average readers on working and short term memory tasks.
\end{abstract}

\section{Background}

Dyslexia is characterized by an explicit and substantial deficiency in the development of reading ability (often accompanied by poor spelling) [1]. According to the ICD-10 published by the WHO (2011), dyslexia occurs whenever an individual's reading skills are significantly lower than their expected potential based on their age, general intelligence, and education [2].

Children with specific learning disorders such as dyslexia or dyscalculia have major problems in acquiring fundamental reading, writing, and arithmetic skills starting from their very first school days [1].

Learning disorders result in secondary problems for many children, such as low self-esteem, school anxiety, depression, psychosomatic disorders, or antisocial behavior and attention deficit disorders (hyperactivity) (ADHD) [1].

Working (WM) and short-term memory (STM) processes were among the most studied cognitive processes in children with reading disabilities (RD) [3].

Tasks that measure STM are generally tasks that do not require change of their initial encoding. This means that participants are not instructed to infer, transform,

\footnotetext{
* Correspondence: nesrinehazem@gmail.com

Faculty of Medicine, Alexandria University, 15 Champolion street,

El-Khartoum Square, El Azarita, Alexandria 21563, Egypt
}

or vary the requirements of processing. Within these situations, participants are specifically asked to recall a string of items in the order in which they were presented. Several authors also suggested that the phonological loop may be considered STM [4] since it involves two key components addressed in the STM literature: a phonological input store based on speech and a rehearsal process [5-8].

Numerous studies suggest that children with reading difficulties do have difficulties with tasks involving short-term retrieval of ordered data which is considered an obvious sign of inadequate phonological recital processing [5-7]. Moreover, another study suggested that tasks assessing STM, including digit or word span tasks, are necessary to distinguish between readers with and without reading difficulties [8].

Research indicates that these children often encounter deficits in the operating of the central executive function yet this deficit tends to fade away when the demand for phonological processing is controlled [9-11].

Furthermore, some studies suggest that reading could also be linked to the control function of the central executive system itself. This is because the central executive system partially controls the phonological loop (i.e., the executive system shares some variance with the phonological loop) [12].

\section{Springer Open}

(c) The Author(s). 2021 Open Access This article is licensed under a Creative Commons Attribution 4.0 International License, which permits use, sharing, adaptation, distribution and reproduction in any medium or format, as long as you give appropriate credit to the original author(s) and the source, provide a link to the Creative Commons licence, and indicate if changes were made. The images or other third party material in this article are included in the article's Creative Commons licence, unless indicated otherwise in a credit line to the material. If material is not included in the article's Creative Commons licence and your intended use is not permitted by statutory regulation or exceeds the permitted use, you will need to obtain permission directly from the copyright holder. To view a copy of this licence, visit http://creativecommons.org/licenses/by/4.0/. 
Working memory (WM) is believed to include a system responsible for keeping verbal and auditory data as well as supporting long-term phonological language representations $[13,14]$.

WM is defined as a low capacity processing resource that is involved in preserving data while handling the same or other data. Tasks measuring WM evaluate the ability of an individual to keep task-relevant information in an active form and regulate controlled processing [15].

Research provided ample evidence that specific learning disabilities are associated with impairments in working memory specifically phonological processing and storage $[11,16,17]$.

Readers with dyslexia often have poor short-term memory for words and problems in phonological manipulation, which necessitates phonological data to be retained while it is being modified $[18,19]$.

Readers with dyslexia were observed to demonstrate poor performance in WM tests such as forward and backward digit span, short-term retention of words through interfering stimuli and task switching, repetition of tapping patterns of increasing lengths, serial comparison, recognition, and recall of words and non-words. This difficulty in keeping and manipulating information may be related to their problems in developing reading skills [20, 21].

\section{Aim of the work}

The purpose of the present study was to compare children with and without dyslexia on measures of shortterm (STM) and working memory (WM) memory tasks.

\section{Methods}

One hundred four children were included in this study. Children were divided into two groups:

Group I: 52 dyslexic children.

Group II: 52 normal children taken as a control group.

Both groups were matched for age, sex, and IQ.

Both groups were subjected to the following protocol of evaluation.

Elementary diagnostic procedures:

- Complete history taking.

- General examination.

- Neurological examination.

Clinical diagnostic procedures:

- Psychometric evaluation: Stanford Binet Scale 4th edition.

- Arabic dyslexia assessment test (ADAT).
- Test of Memory and Learning (TOMAL-2nd edition): [22] Subjects were assessed by eight core (memory for stories, word selective reminding, object recall, paired recall, facial memory, abstract visual memory, visual sequential memory, memory for location) and six supplementary subtests (digits forwards, letters forwards, digits backwards, letters backwards, visual selective reminding, manual imitation). The core subtests were aggregated to produce a Verbal Memory Composite Index (memory for stories, word selective reminding, object recall, paired recall) and a Non-verbal Memory Composite Index (facial memory, abstract visual memory, visual sequential memory, memory for location). A detailed description of all tasks follows below.

\section{Core subtests}

Verbal Memory Composite Index

- The memory for stories (MFS) requires the verbal free-recall of two orally presented stories of increasing complexity. In the word selective reminding (WSR), the examinees are required to correctly recall an aurally presented list of words. The examinee is then asked to repeat the list of words; however, only omitted words are provided before the examinee is asked to recall all of the words again. In the object recall (OR), the examiner presents a series of 15 illustrations on an easel page and then provides the names for each object. The examinee is then required to verbally express the name of the illustration provided by the examiner. The paired recall (PR) is a paired-associate task which requires the examinee to verbally recall a word when provided the word with which it was paired during learning trials.

\section{Non-verbal Memory Composite Index}

Facial memory (FM) is a non-verbal task that assesses recognition of faces in the presence of distraction. Examinees are shown up to 12 photos of different faces (targets) and asked to recall the target face while presented with other faces not shown (distracters). Unlike the facial memory subtest which taps recognition of meaningful, non-verbal information, the abstract visual memory (AVM) subtest measures recognition of abstract stimuli. Examinees are presented with a single geometric figure on an easel page and then the examinee must recognize the figure among a series of six abstract stimuli. During the visual sequential memory (VSM), examinees are horizontally presented abstract designs and are then required to indicate the order in which they were presented on a separate easel page when given the same designs in a random order. The memory for location (MFL) subtest assesses spatial memory by requiring 
examinees to recall the location of dots dispersed across a picture book page. After viewing the initial stimulus, examinees must then place plastic chips on a grid representing locations on which the dots were presented.

\section{Supplementary subtests}

The digits forwards (DF) subtest is a traditional digits recall subtest. A series of 2 to 10 digits is presented acoustically at a rate of 1 digit per second, starting with 2 and continuing up to a maximum of 10 digits. Participants had to repeat the digits immediately in the presented order. The same applies to the digits backwards (DB) subtest, except the correct placement of a digit in reverse order is required. Letters forward (LF) and letters backward (LB) subtests are offered as "language-related" correlates to the digits subtests. The premise of the manual imitation (MI) subtest is similar to aforementioned subtests except the stimuli response modality involves four different hand positions. The visual selective reminding (VSR) subtest is described as a non-verbal analog to word selective reminding.

\section{Statistical methodology}

Data were collected and entered to the computer using SPSS (Statistical Package for Social Science) program for statistical analysis (ver 21) [23]. Data were entered as numerical or categorical, as appropriate.

Kolmogorov-Smirnov test of normality revealed significance in the distribution of some variables, so the non-parametric statistics was adopted [24].

Data were described using minimum, maximum, mean, standard deviation and $95 \% \mathrm{CI}$ of the mean [25], median, and inter-quartile range.

Categorical variables were described using frequency and percentage.

Comparisons were carried out between two studied independent not-normally distributed subgroups using Mann-Whitney $U$ test [26].

Comparisons were carried out between more than two studied independent not-normally distributed subgroups using Kruskal-Wallis test [27].

Post hoc pair-wise comparisons when Kruskal-Wallis test was significant was carried out using Dunn-Sidak test for multiple comparison [28].

Chi-square test was used to test association between qualitative variables. Monte Carlo corrections [29] were carried out when indicated $(n \times m$ table).

Box and whiskers plot and bar chart were used accordingly.

An alpha level was set to $5 \%$ with a significance level of $95 \%$, and a beta error accepted up to $20 \%$ with a power of study of $80 \%$.

\section{Results}

Fifty-two dyslexic school-aged children and 52 normal children participated in this study. Both groups were matched for age and sex (Figs. 1 and 2). There was no statistically significant difference between verbal I.Q., abstract visual I.Q., and general I.Q. in the studied groups ( $p=0.377, p=0.100, p=0.624$, respectively). A statistically significant difference was found regarding the verbal and non-verbal memory composite indexes of the core battery as well as all items of the supplementary subtest $(p=0.000)$ (Tables 1,2 , and 3$)$

\section{Discussion}

Our research results revealed that the dyslexic group showed significantly lower performance on all test items relative to their control group matched by age and IQ. This implies that memory deficits accompany learning disorders such as dyslexia. In terms of educational implications, the important role of short-term and working memory for school achievement should be taken into account. It was argued that short-term and working memory could be more predictive than intelligence for school achievement

Verbal working memory is likely to play a major role in reading whether memory deficits per se emerge as a primary factor or as a contributing factor in reading disability.

Like others, we found that on verbal memory, the groups differed significantly. Compared to the control group, the dyslexic group scored significantly lower in the Verbal Memory Composite Index.

In earlier research, dyslexia-related verbal STM deficiency was interpreted primarily as a result of impaired phonological representations. Based on the phonological core deficit hypothesis of dyslexia [30], dyslexic children's phonological representations are degraded and block effective retrieval of verbal stimuli in STM tasks along with phonological awareness and rapid automatic naming tasks, all of which depend on activating phonological representations.

In the context of the models differentiating between serial order and item STM abilities, the interpretation of verbal STM defects in dyslexia as a result of compromised phonological representations implicitly corresponds to the assumption that there is an item STM defect, since item information processes rely directly on the quality of the language network as shown previously [31]. Weak readers frequently lack the ability to recall linguistic information and the problem seems to be attributed to phonological processes involved in the encoding or storage of verbal data. Children who are poor readers are continually performing poorly in recall level compared to their age mates. 


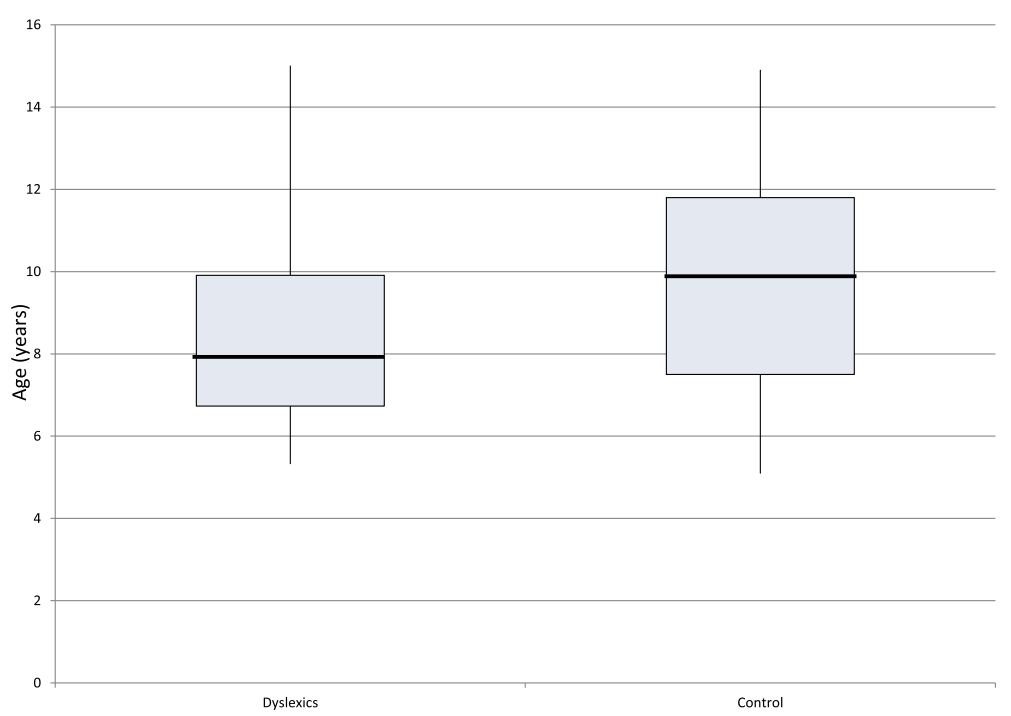

Fig. 1 Box and whisker graph of age (years) in the studied groups; the thick line in the middle of the box represents the median, the box represents the inter-quartile range (from 25th to 75th percentiles), and the whiskers represents the minimum and maximum after excluding outliers (black-filled circles). (Numbers indicate the serial number of the patient in the original master table)

In Baddeley's model, the visual-spatial sketchpad is specialized for the processing and storage of visual material, spatial material, or both as well as for linguistic information that can be coded into conceivable forms. The literature that links dyslexia to the visual-spatial memory defects is mixed. Many of the studies found that visual-spatial WM was preserved in children with dylexia compared to their counterparts of the same age [32, 33], while other studies suggested visual-spatial problems in dyslexic children $[32,33]$.
Learning disorders such as dyslexia and dyscalculia and attention deficit disorders are accompanied by specific work memory deficits: phonological loop is affected in children with dyslexia, visual-spatial sketchpad is affected in children with dyscalculia, and children with ADHD have difficulties in the central executive tasks.

The high incidence of dyslexia comorbidity with dyscalculia and attention deficit hyperactivity disorders [34] tends to lead to common cognitive impairments and could have resulted in the significant difference in the non-verbal composite memory index in this study.

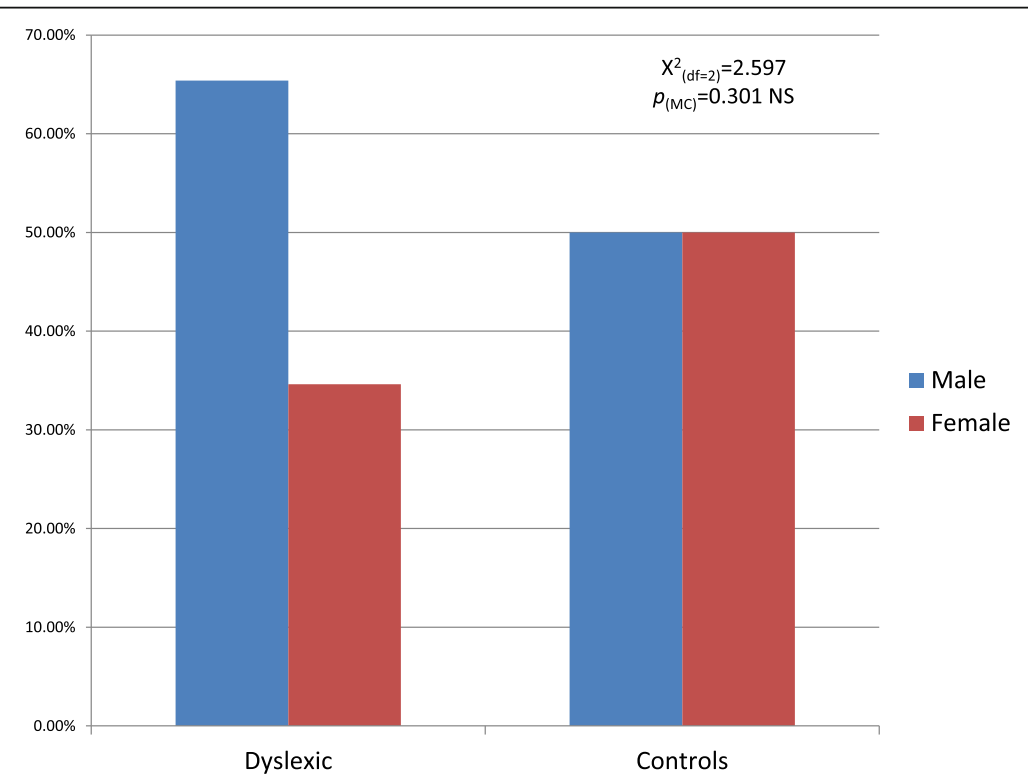

Fig. 2 Clustered bar chart of sex in the studied groups 
Table 1 Comparison between the two studied groups according to the core subtests

\begin{tabular}{|c|c|c|c|}
\hline & Dyslexic group & Control group & $\begin{array}{l}\text { Test of significance } \\
\text { ( } p \text { value) }\end{array}$ \\
\hline \multicolumn{4}{|c|}{ Verbal Memory Composite Index (VMI) } \\
\hline $\begin{array}{l}n \\
\text { Min-max } \\
\text { Median (IQR) }\end{array}$ & $\begin{array}{l}52 \\
45.00-109.00 \\
70.50^{\mathrm{a}, \mathrm{b}}(63.00-78.00)\end{array}$ & $\begin{array}{l}52 \\
80.00-147.00 \\
107.00^{\complement}(101.00-121.00)\end{array}$ & $\begin{array}{l}X_{(\mathrm{KW})(\mathrm{df}=2)}^{2}=74.924 \\
p=0.000^{*}\end{array}$ \\
\hline \multicolumn{4}{|c|}{ Non-verbal Memory Composite Index (NMI) } \\
\hline $\begin{array}{l}-n \\
\text { - Min-max } \\
\text { - Median (IQR) }\end{array}$ & $\begin{array}{l}52 \\
45.00-123.00 \\
73.00^{\mathrm{a}, \mathrm{b}}(66.00-82.00)\end{array}$ & $\begin{array}{l}52 \\
82.00-142.00 \\
102.00^{C}(97.00-116.00)\end{array}$ & $\begin{array}{l}x^{2}(\mathrm{~kW})(\mathrm{df}=2)=51.526 \\
p=0.000^{*}\end{array}$ \\
\hline
\end{tabular}

$n$ number, Min-max minimum-maximum, IQR inter-quartile range, $K W$ Kruskal-Wallis test, $d f$ degree of freedom

*Statistically significant difference $(p<0.05)$

NS statistically no significant difference $(p>0.05)$

It is assumed that the number reversed task is primarily a short-term measure of processing capacity. Colom et al. (2005) [35] described forward and backward span measures as similar STM storage measures [35].

In the dyslexia group, with both forward and backward digits and letters span tasks, the serial ordering of responses was impaired. Location memory was as well deficient. The pattern looks similar in terms of visual sequential memory, visual selective recall, and manual imitation and shows a compelling significant difference.

Multiple studies have suggested that children with reading difficulties often have difficulties with tasks that require the short-term retention of ordered information indicating of ineffective phonological rehearsal [6, 7]. Moreover, numerous researches [8] suggested that tasks measuring STM, such as digit or word span tasks, are essential in distinguishing readers with and without reading disability.

Children with dyslexia may have a deficit in using strategies to preserve serial order, thus showing a deficiency in standard span tasks.

Dyslexia is partly due to children losing track of the unit order they are reading. That is, there could be a causal association between short term serial order memory and reading ability. Letter series must be kept in working memory until words are identified and words and phrases must be kept in working memory until the underlying ideas are identified.

The possible explanation why children with dyslexia tend to be disadvantaged with regard to children with typical development in serial order within standard digit span could be

Table 2 Comparison between the studied groups as regards supplementary (verbal subsets)

\begin{tabular}{|c|c|c|c|}
\hline & Dyslexic group & Control group & $\begin{array}{l}\text { Test of significance } \\
\text { ( } p \text { value) }\end{array}$ \\
\hline \multicolumn{4}{|c|}{ Digits forwards (DF) } \\
\hline $\begin{array}{l}-n \\
\text { - Min-max } \\
\text { - Median (IQR) }\end{array}$ & $\begin{array}{l}52 \\
5.00-12.00 \\
7.00(6.00-7.00)\end{array}$ & $\begin{array}{l}52 \\
8.00-18.00 \\
12.00(11.00-13.50)\end{array}$ & $\begin{array}{l}x^{2}(\mathrm{~kW})(\mathrm{df}=2)=76.121 \\
p=0.000^{*}\end{array}$ \\
\hline \multicolumn{4}{|c|}{ Letters forwards (LF) } \\
\hline $\begin{array}{l}-n \\
\text { - Min-max } \\
\text { - Median (IQR) }\end{array}$ & $\begin{array}{l}52 \\
4.00-13.00 \\
7.00(7.00-7.00)\end{array}$ & $\begin{array}{l}52 \\
7.00-18.00 \\
11.00(9.50-13.50)\end{array}$ & $\begin{array}{l}x^{2}(\mathrm{KW})(\mathrm{df}=2)=68.944 \\
p=0.000^{*}\end{array}$ \\
\hline \multicolumn{4}{|c|}{ Digits backwards (DB) } \\
\hline $\begin{array}{l}-n \\
\text { - Min-max } \\
\text { - Median (IQR) }\end{array}$ & $\begin{array}{l}52 \\
1.00-13.00 \\
7.00^{a, b}(5.00-7.00)\end{array}$ & $\begin{array}{l}52 \\
8.00-17.00 \\
11.00^{C}(9.00-12.50)\end{array}$ & $\begin{array}{l}x^{2}(\mathrm{KW})(\mathrm{df}=2)=63.865 \\
p=0.000^{*}\end{array}$ \\
\hline \multicolumn{4}{|c|}{ Letters backwards (LB) } \\
\hline $\begin{array}{l}-n \\
\text { - Min-max } \\
\text { - Median (IQR) }\end{array}$ & $\begin{array}{l}52 \\
4.00-11.00 \\
7.00^{\mathrm{a}, \mathrm{b}}(6.00-7.00)\end{array}$ & $\begin{array}{l}52 \\
8.00-17.00 \\
10.00^{C}(9.00-12.00)\end{array}$ & $\begin{array}{l}x^{2}(\mathrm{KW})(\mathrm{df}=2)=73.732 \\
p=0.000^{*}\end{array}$ \\
\hline
\end{tabular}

$n$ number, Min-max minimum-maximum, $I Q R$ inter-quartile range, $K W$ Kruskal-Wallis test, $d f$ degree of freedom

*Statistically significant difference $(p<0.05)$

$N S$ statistically no significant difference $(p>0.05)$ 
Table 3 Comparison between the studied groups as regards supplementary (non-verbal subsets)

\begin{tabular}{|c|c|c|c|}
\hline & Dyslexic group & Control group & $\begin{array}{l}\text { Test of significance } \\
\text { ( } p \text { value) }\end{array}$ \\
\hline \multicolumn{4}{|c|}{ Visual selective reminding (VSR) } \\
\hline $\begin{array}{l}-n \\
\text { - Min-max } \\
\text { - Median (IQR) }\end{array}$ & $\begin{array}{l}52 \\
2.00-15.00 \\
7.00^{\mathrm{a}, \mathrm{b}}(5.00-7.00)\end{array}$ & $\begin{array}{l}52 \\
8.00-15.00 \\
11.00^{C}(9.00-13.00)\end{array}$ & $\begin{array}{l}x^{2}(\mathrm{KW})(\mathrm{df}=2)=56.511 \\
p=0.000^{*}\end{array}$ \\
\hline \multicolumn{4}{|c|}{ Manual imitation (MI) } \\
\hline $\begin{array}{l}-n \\
\text { - Min-max } \\
\text { - Median (IQR) }\end{array}$ & $\begin{array}{l}52 \\
5.00-16.00 \\
7.00^{\mathrm{a}, \mathrm{b}}(6.00-7.00)\end{array}$ & $\begin{array}{l}52 \\
6.00-18.00 \\
11.00^{C}(9.00-13.00)\end{array}$ & $\begin{array}{l}x^{2}(\mathrm{KW})(\mathrm{df}=2)=53.125 \\
p=0.000^{*}\end{array}$ \\
\hline
\end{tabular}

$n$ number, Min-max minimum-maximum, $I Q R$ inter-quartile range, $K W$ Kruskal-Wallis test, $d f$ degree of freedom,

*Statistically significant difference $(p<0.05)$

NS statistically no significant difference $(p>0.05)$

that children with dyslexia are poorer at the covert verbal rehearsal that has been proposed as a mnemonic strategy that adults use [36] and is just emerging at this age in children with typical development [33, 37].

The results regarding dyslexia appear to be consistent with previous work which supports the theory that serial order memory is compromised in dyslexic children particularly in comparison to typically developing individuals. Our results support the conclusion that a serial order memory deficit exists [33].

\section{Conclusions}

Dyslexic children are distinctively disadvantaged compared with average readers on working and short-term memory tasks.

Assessment of working and short-term memory can be an integral part of the evaluation protocol of dyslexic children. Incorporating memory training strategies and phonological awareness in rehabilitation of dyslexic children.

\section{Abbreviations}

STM: Short-term memory; TOMAL-2: Test of Memory and Leaning-Second Edition; ICD: International Classification of Disease; ADHD: Attention deficit hyperactivity disorders; WM: Working memory; RD: Reading disability;

ADAT: Arabic dyslexia assessment test; MFS: Memory for stories; WS: Word selective reminding; OR: Object recall; PR: Paired recall; FM: Facial memory; AVM: Abstract visual memory; VSM: Visual sequential memory; MFL: Memory for location; DF: Digits forwards; DB: Digits backwards; LF: Letters forward; LB: Letters backward; MI: Manual imitation; VSR: Visual selective reminding

\section{Acknowledgements}

The authors acknowledge all study participants.

\section{Authors' contributions}

$\mathrm{NHH}$ gave idea, supervised the stages of the research, helped with study design, put study design, and wrote the paper. RAE collected the data and followed the cases. They all read and approved the final version of the manuscript.

\section{Funding}

This study received no funding.
Availability of data and materials

The datasets used and/or analyzed during the current study are available from the corresponding author on reasonable request.

\section{Ethics approval and consent to participate}

This study was approved by the Research Ethics Committee of the Faculty of Medicine, Alexandria University in Egypt on 17 June 2019; reference number of approval: 0304350 . All parents of patients included in this study gave written informed consent to participate in this research.

\section{Consent for publication}

Not applicable.

\section{Competing interests}

The authors declare that they have no competing interests.

Received: 11 June 2020 Accepted: 16 December 2020

Published online: 13 January 2021

\section{References}

1. Maehler C, Schuchardt K (2016) Working memory in children with specific learning disorders and/or attention deficits. Learn Individ Diff 49:341-347

2. World Health Organization (WHO) (2011) ICD: Classification of mental and behavioural disorders:bClinical descriptions and diagnostic guidelines (10th rev. ed.). WHO, Geneva

3. Swanson H, Cooney JK, McNamara J (2004) Learning Disabilities and Memory. In: Wong B (ed) Learning About Learning Disabilities, 3rd edn. Elsevier Inc, USA, pp 41-92

4. Baddeley AD (1986) Working memory. Oxford University Press, Oxford

5. McDougall S, Hulme C, Ellis A, Monk A (1994) Learning to read: the role of short-term memory and phonological skills. J Exp Child Psychol 58(1):112-133

6. Swanson HL, Cooney JB, O'Shaughnessy TE (1998) Learning disabilities and memory. In: Wong BY (ed) Understanding learning and learning disabilities. Academic, San Diego, pp 107-162

7. Henry LA, Millar S (1993) Why does memory span improve with age? A review of the evidence for two current hypotheses. Eur J Cogn Psychol 5(3): 241-287

8. Torgesen JK, Houck DG (1980) Processing deficiencies of learning-disabled children who perform poorly on the Digit Span Test. J Educ Psychol 72(2): $141-160$

9. Brandenburg J, Klesczewski J, Fischbach A, Schuchardt K, Buttner G, Hasselhorn M (2015) Working memory in children with learning disabilities in reading versus spelling: searching for overlapping and specific cognitive factors. J Learn Disabil 48(6):622-634

10. Landerl K, Bevan A, Butterworth B (2004) Developmental dyscalculia and basic numerical capacities: a study of 8-9-year-old students. Cognition 93(2): 99-125

11. Schuchardt K, Maehler C, Hasselhorn M (2008) Working memory deficits in children with specific learning disorders. J Learn Disabil 41(6):514-523 
12. Swanson HL, Alexander JE (1997) Cognitive processes as predictors of word recognition and reading comprehension in learning-disabled and skilled readers: revisiting the specificity hypothesis. J Educ Psychol 89(1):128

13. Gathercole SE, Tiffany C, Briscoe J, Thorn A (2005) Developmental consequences of poor phonological short-term memory function in childhood: a longitudinal study. J Child Psychol Psychiatry 46(6):598-611

14. Schwarb H, Nail J, Schumacher EH (2016) Working memory training improves visual short-term memory capacity. Psychol Res 80(1):128-148

15. Unsworth N, Engle RW (2007) On the division of short-term and working memory: an examination of simple and complex span and their relation to higher order abilities. Psychol Bull 133(6):1038-1066

16. Alloway TP, Gathercole SE (2006) Working memory and neurodevelopmental disorders. Psychology Press, Hove

17. Pickering SJ (2006) Working memory and education. Academic, San Diego

18. Verhagen J, Leseman P (2016) How do verbal short-term memory and working memory relate to the acquisition of vocabulary and grammar? A comparison between first and second language learners. J Exp Child Psychol 141:65-82

19. Fostick L, Revah H (2018) Dyslexia as a multi-deficit disorder: Working memory and auditory temporal processing. Acta Psychol 183:19-28

20. Garcia RB, Mammarella IC, Tripodi D, Cornoldi C (2014) Visuospatial working memory for locations, colours, and binding in typically developing children and in children with dyslexia and non-verbal learning disability. Br J Dev Psychol 32(1):17-33

21. Zhao J, Yang Y, Song YW, Bi HY (2015) Verbal Short-Term Memory Deficits in Chinese Children with Dyslexia may not be a Problem with the Activation of Phonological Representations. Dyslexia 21(4):304-322

22. Schmitt AJ, Decker SL (2007) Test Reviews. In: Reynolds C, Voress JK (eds) Test of memory and learning. PRO-ED, Austin

23. IBM Corp (2012) IBM SPSS statistics for Windows, version 21.0. IBM Corp, Armonk

24. Field A (2013) Discovering statistics using IBM SPSS statistics. SAGE Publications, Thousand Oaks

25. Snecdecor GW, Cochran WG (1991) Statistical Methods. Wiley, UK

26. Mann HB, Whitney DR (1947) On a test of whether one of two random variables is stochastically larger than the other. Ann Math Stat:50-60

27. Kruskal WH, Wallis WA (1952) Use of ranks in one-criterion variance analysis. J Am Stat Assoc 47(260):583-621

28. Dunn OJ (1964) Multiple comparisons using rank sums. Technometrics 6(3): $241-252$

29. Benjamini $Y$, Hochberg $Y$ (1995) Controlling the false discovery rate: a practical and powerful approach to multiple testing. J R Stat Soc Series B Stat Methodol 57(1):289-300

30. Ramus F (2003) Developmental dyslexia: specific phonological deficit or general sensorimotor dysfunction? Curr Opin Neurobiol 13(2):212-218

31. Majerus S, D'Argembeau A (2011) Verbal short-term memory reflects the organization of long-term memory: Further evidence from short-term memory for emotional words. J Mem Lang 64(2):181-197

32. Swanson HL, Ashbaker MH, Lee C (1996) Learning-disabled readers' working memory as a function of processing demands. J Exp Child Psychol 61(3): $242-275$

33. Cowan N, Hogan TP, Alt M, Green S, Cabbage KL, Brinkley S et al (2017) Short-term Memory in Childhood Dyslexia: Deficient Serial Order in Multiple Modalities. Dyslexia 23(3):209-233

34. DuPaul GJ, Gormley MJ, Laracy SD (2013) Comorbidity of LD and ADHD: implications of DSM-5 for assessment and treatment. J Learn Disabil 46(1): 43-51

35. Colom R, Abad FJ, Rebollo I, Shih PC (2005) Memory span and general intelligence: A latent-variable approach. Intelligence 33(6):623-642

36. Camos V, Mora G, Oberauer K (2011) Adaptive choice between articulatory rehearsal and attentional refreshing in verbal working memory. Mem Cognit 39(2):231-244

37. Cowan N, Elliott EM, Scott Saults J, Morey CC, Mattox S, Hismjatullina A et al (2005) On the capacity of attention: its estimation and its role in working memory and cognitive aptitudes. Cogn Psychol 51(1):42-100

\section{Publisher's Note}

Springer Nature remains neutral with regard to jurisdictional claims in published maps and institutional affiliations.

\section{Submit your manuscript to a SpringerOpen ${ }^{\circ}$ journal and benefit from:}

- Convenient online submission

- Rigorous peer review

- Open access: articles freely available online

- High visibility within the field

- Retaining the copyright to your article

Submit your next manuscript at $\boldsymbol{\nabla}$ springeropen.com 